\title{
Sleepless in Macao: Factors Associated with Sleep Behaviour and Sleep Duration among Children in Public and Private Schools
}

\author{
Cindy Sin U Leong ${ }^{1, *}$, Thomas Kwok Shing Wong ${ }^{2}$ \\ ${ }^{1}$ School of Health Science, Macao Polytechnic Institute, Macao \\ ${ }^{2}$ Tung Wah College, Hong Kong
}

\begin{abstract}
To evaluate the associations of socioeconomic class (middle and lower) with sleep behaviour, two public and two private primary schools were randomly selected in three district areas (out of seven) in Macao, China. The sleep behaviour of these children (primary grades one to six) was examined with a validated, locally developed questionnaire. In all, $756(83.3 \%)$ of the 908 questionnaires were completed and returned, 330(43.7\%) for girls and 426(56.3\%) for boys. Only $142(19.9 \%)$ children reached the recommended standard of 10 hours of daily sleep on weekdays that were not during an exam period. Thus, $571(80.1 \%)$ did not get the required sleep $\left(\mathrm{x}^{2}=9.748\right.$; degrees of freedom $\left.[\mathrm{df}]=1 ; \mathrm{P}=0.002\right)$. The situation was even worse in exam periods during weekdays, with $626\left(87.6 \% ; \mathrm{x}^{2}=19.406 ; \mathrm{df}=1 ; \mathrm{P}=0.000\right)$ children not obtaining 10 hours of sleep during that time. These results show that improper sleep behaviour in Macao children is associated with stressed school workload, bedtime difficulty, and environmental factors. Early intervention on these factors might help the children to establish adequate sleep habits.
\end{abstract}

Keywords Primary Schools, Sleep, Socioeconomic Factor, Environmental Factor

\section{Introduction}

Inadequate sleep duration has become a major problem in recent years and is now a worldwide phenomenon[1-6] Moreover, studies in the United States, Europe, and Asia have found that inadequate sleep is becoming more common in both Western and Eastern countries. In addition, numerous research studies indicate that children are gradually decreasing the amount of time they sleep[7] Theoretically, inadequate sleep could cause children to underachieve in school and to have problems in both physical and mental function. In the United States, a report[8]found that $24 \%$ of U.S. children slept less than the recommended 10 hours overall, the average was 9.5 hours. In European countries like Finland, Greece, Italy, Switzerland, and the United Kingdom the problem has been reported as well[9-13], and studies from Asian countries such as China, Korea, and Japan show an even worse picture, with reported sleep duration ranging from 7.5 down to 4.86 hours[14-16]. An estimated $30 \%$ of children have a hard time falling asleep[17], and, unfortunately, inadequate sleep behavior can increase the risks among children of various physio logical or

\footnotetext{
* Corresponding author:

suleong@ipm.edu.mo (Cindy Sin U Leong)

Published online at http://journal.sapub.org/phr

Copyright $\left({ }^{\circ} 2011\right.$ Scientific \& Academic Publishing. All Rights Reserved
}

psychological problems, such as obesity, hyperactivity, and being easily irritated[18-21] There can be a variety of causes; for some children their sleep problems may be related to activities that increase their level of alertness and physiological arousal. External factors, such as school, family, and personal issues[22], or internal factors, whether a personal history of difficulty in falling asleep, past traumatic experience, or health problems[23], may be causative. Regardless, improper sleep behavior may make it more difficult for children to perform well in school or to solve problems, whether in school or a social relationship. In addition, children with sleep problems are at high risk for drug and alcohol use[24-25] Therefore, in the present study it was hypothesized that children with higher scores in percentage in variables of sleep behavior would have better sleep duration.

\section{Methods}

\subsection{Participants}

The participants came from two public and two private primary schools in Macao, a special administrative region of China. Of 908 questionnaires that were distributed on sleep behaviour, $756(83.3 \%)$ were completed and returned. Of these, $330(43.7 \%)$ were for girls and $426(56.3 \%)$ were for boys. The participants, who were in primary grades one to 
six, ranged in age from 6 to 12 years. The research project was approved by the board of ethics review of The Hong Kong Polytechnic University. All the children were consented by their parents or family members. They were sure that even researchers did not know the sleep behaviour for whose children.

\subsection{Instruments}

The survey was a locally developed questionnaire based on interviews with 14 children and their parents that relied on 20 semi-structured questions. Those question-items with a content validity index(CVI) above 3 points in the interviews were retained. Test-retest reliability was assessed by having 12 students( 6 girls and 6 boys) from primary one to primary six attending different schools respond to the questions. The maximum score for Spearman's rho on the completed surveys was 0.88 , with a standard deviation of 0.11 . The mean value for Spearman correlation was 0.69 , and the $\mathrm{P}$ was either less than 0.05 or 0.01 on the whole. Cronbach's alpha ranged from 0.41 to 0.90 for the different concepts. A Cronbach's alpha of greater than 0.5 was accepted for the survey. In the end, a total of 46 items were combined with an additional eight items that related to hours of sleep on weekdays and on weekends during test or exam periods, or without test or exam periods.

\subsection{Procedures}

One of the two private schools had three classes in each primary grade, and the other had five; each class had around 40 to 45 students. In all, there were 48 classes in the six primary grades in these two schools. The two public schools had one class in each grade, with fewer than 45 students per class on average. Students were selected for the study using a random number generator system chosen from a Web site (http://www.random.org/integers/); each student had been assigned a number for the selection process. All the classes in both the public and private schools participate. A package containing a consent form and questionnaire with two envelopes was delivered to the selected students by their teachers. Two boxes, one for the consent form and the other for the questionnaire, were left in the schools to allow the students and parents to drop off the two envelopes personally. After waiting for around 1 to 3 weeks, with the teachers reminding students about completing the forms and after returns appeared to have stopped, the researcher collected the boxes from these schools. Data on the return questionnaires was first entered in Excel format(Microsoft Corporation, Redmond, Washington) and then transformed to SPSS format for analysis.

\section{Results}

The demographic data involved categorical variables, and thus the chi-square test was used to assess the differences between public and private schools. Of 749 surveys, $37.5 \%$ were completed by the mothers in private schools, while
$22.0 \%$ of the surveys were filled out by students in the public schools $(\mathrm{N}=749, \mathrm{x} 2=136.75$; degrees of freedom $[\mathrm{df}]=3, \mathrm{P}$ $=0.000)$. The parents of the public school students might have had relatively lower level of educational levels, or they might have been on shifts in their work and thus unable to complete the form. Thus, the students from the public schools may have lived more independent lives. Significant differences between public and private schools were seen for six of the seven categorical variables in Table 1(all except gender).

Table 1. Significant differences between public and private schools in demographics $(\mathrm{N}=756)$

\begin{tabular}{|c|c|c|c|c|c|c|}
\hline \multirow[b]{2}{*}{ Variable } & & \multicolumn{2}{|c|}{ School } & \multirow[b]{3}{*}{$x^{2}$} & \multirow[b]{3}{*}{$\mathrm{df}$} & \multirow[b]{3}{*}{$P$ (2-sided) } \\
\hline & & Public & Private & & & \\
\hline & & $\mathrm{N}$ & $\mathrm{N}$ & & & \\
\hline \multirow[t]{2}{*}{ Gender } & Girls & 111 & 219 & \multirow{2}{*}{0.496} & \multirow{2}{*}{1} & \multirow{2}{*}{0.481} \\
\hline & Boys & 133 & 293 & & & \\
\hline \multirow[t]{5}{*}{ Grade } & $91-100$ & 11 & 64 & \multirow{5}{*}{113.195} & \multirow{5}{*}{5} & \multirow{5}{*}{0.000} \\
\hline & $81-90$ & 55 & 215 & & & \\
\hline & $71-80$ & 79 & 171 & & & \\
\hline & $61-70$ & 65 & 56 & & & \\
\hline & Other & 2 & 1 & & & \\
\hline \multirow{5}{*}{$\begin{array}{l}\text { Extracurricular } \\
\text { activity }\end{array}$} & $\geqq 5$ times/wk & 26 & 49 & \multirow{5}{*}{59.696} & \multirow{5}{*}{4} & \multirow{5}{*}{0.000} \\
\hline & 3-4 times/wk & 33 & 112 & & & \\
\hline & $1-2$ times/wk & 88 & 267 & & & \\
\hline & Rare & 64 & 63 & & & \\
\hline & None & 43 & 28 & & & \\
\hline \multirow{5}{*}{$\begin{array}{l}\text { Sactisfaction } \\
\text { with school life }\end{array}$} & Strongly like & 58 & 152 & \multirow{5}{*}{10.233} & \multirow{5}{*}{4} & \multirow{5}{*}{0.037} \\
\hline & Like & 118 & 250 & & & \\
\hline & Fair & 70 & 111 & & & \\
\hline & Don't like & 5 & 3 & & & \\
\hline & Strongly don't like & 2 & 1 & & & \\
\hline \multirow[t]{5}{*}{ Friendship } & Strongly harmonious & 58 & 138 & \multirow{5}{*}{27.428} & \multirow{5}{*}{4} & \multirow{5}{*}{0.000} \\
\hline & Harmonious & 115 & 294 & & & \\
\hline & Fair & 76 & 79 & & & \\
\hline & Unharmonious & 1 & 5 & & & \\
\hline & Strongly unharmonious & 3 & 1 & & & \\
\hline \multirow[t]{4}{*}{ Family income } & $<\$ 4,000$ & 54 & 5 & \multirow{4}{*}{425.908} & \multirow{4}{*}{3} & \multirow{4}{*}{0.000} \\
\hline & $\$ 4,000-\$ 9,999$ & 118 & 19 & & & \\
\hline & $\$ 10,000-\$ 19,999$ & 56 & 120 & & & \\
\hline & $\geqq \$ 20,000$ & 13 & 371 & & & \\
\hline \multirow[t]{2}{*}{$\begin{array}{l}\text { Family } \\
\text { members }\end{array}$} & Parents only & 158 & 360 & 3989 & 1 & 0.046 \\
\hline & Others & 95 & 157 & & & \\
\hline
\end{tabular}

Note: Macao patacas of $\$ 8.05 \fallingdotseq$ US $\$ 1.00$

In terms of grades received in school, the most common category for public students was 71-80(37.3\%), while for private students it was $81-90(42.4 \%)$. The second-most common category for students in public schools was 61-70, while 71-80 ranked second for private students. For both public and private students, 1-2 times a week was the most common amount of extracurricular activity: $88(34.6 \%)$ and $267(51.5 \%)$ students, respectively. The second-ranked amount was "rare" for public students(25.2\%) but "3-4 times/week" for private students(21.6\%). For satisfaction with school life, approximately half of the students were classified as "like," while "harmonious" was easily the most popular category for friendship. Ranking second for public schools was "fair" for both satisfaction with school life and friendship, while in private school "strongly like" and strongly harmonious" ranked second, respectively. Family income in public schools was $\$ 4,000$ - $\$ 9,999$ almost half of the participants $(49.0 \%$ ), while in private schools it was usu- 
ally $\$ 20,000$ or more $(72.0 \%)$. The vast majority of the students were living with their parents only(Table 1). There were only one class in grade one and grade two in public schools.

Table 2. Comparisons of sleep behaviour variables that differed significantly between public and private schools

\begin{tabular}{ccccccc}
\hline & \multicolumn{5}{c}{ School } & \\
\cline { 2 - 5 } Variable & Public & \multicolumn{1}{c}{ Private } & \\
\hline & $\mathrm{N}$ & $\%$ & $\mathrm{~N}$ & $\%$ & $\mathrm{x}^{2}$ & $\begin{array}{c}P \\
\text { value }\end{array}$ \\
\hline $\begin{array}{c}\text { Personal hygiene before sleep } \\
\text { Take shower }\end{array}$ & 217 & 85.4 & 486 & 93.6 & 16.04 & 0.000 \\
Change clothes & 211 & 83.1 & 500 & 96.2 & 39.22 & 0.000 \\
Brush teeth & 210 & 83.3 & 500 & 96.2 & 37.88 & 0.000
\end{tabular}

\section{Sleep pattern during school terms Parents wake me up \\ Unable to get up as a result of many activities yesterday Wake up by self \\ Wake up by alarm clock \\ $\begin{array}{llllll}141 & 55.7 & 378 & 72.7 & 22.42 & 0.000\end{array}$ \\ $\begin{array}{llllll}83 & 32.9 & 240 & 46.4 & 13.75 & 0.001\end{array}$ \\ $\begin{array}{llllll}68 & 26.9 & 232 & 44.7 & 38.23 & 0.000\end{array}$ \\ $\begin{array}{llllll}70 & 28.0 & 180 & 34.8 & 17.37 & 0.000\end{array}$}

School workload

Delay bedtime due to test or exam $\quad \begin{array}{llllll}101 & 40.2 & 323 & 62.4 & 38.89 & 0.000\end{array}$ Feel sleepy even with adequate amount of sleep

Unable to concentrate in class

Delay of 2 hours to bed on weekends or holidays

Same wake-up time on school days and weekends

Much school work affects my bedtime

Inadequate sleep affects school performance

Unable to wake up early result of delayed bedtime last night

\section{Sleep habits}

Parents accompany to sleep

Storytelling to accompany sleep

Easy to fall asleep with parents as companions

\section{Extracurricular activities}

Need to attend private lessons after school

Already 6 pm or later after having private lessons

Not allowed to watch TV or play

computer games on school days

\section{Environmental factors}

Neighborhood noise

Parents' arguments affect my sleep

Uncomfortable bedroom affects my sleep

Note: $\mathrm{df}=2$ for all variables.

Table 2 displays 24 variables with a relation to sleep behaviour that differed significantly $(\mathrm{P}<0.05)$ between public and private schools using the chi-square test for associations (an additional 22 variables had been examined but did not yield significant differences by type of school). In four of the six major categories - personal hygiene before sleep, sleep pattern during school terms, sleep habits, and extracurricular activities - the children in private schools had significantly higher scores than those in public schools on all of the individual variables. For the category of school workload, participants in private schools scored lower on three variables feel sleepy even with adequate amount of sleep, unable to concentrate in class, and same wake-up time on school days and weekends - while scoring higher on the other four. Finally, for environmental factors, private schools had lower scores on all three variables: neighborhood noise, parents' arguments affect my sleep, and an uncomfortable bedroom affects my sleep.

Table 3. Comparison of sleep duration between public and private schools

\begin{tabular}{|c|c|c|c|c|c|}
\hline & & & hool & & \\
\hline Variable & & Public & Private & & \\
\hline $\begin{array}{l}\text { Sleep duration in non-exam } \\
\text { period on weekdays }\end{array}$ & $\geqq 10$ hours & 57 & 85 & 9.748 & 0.002 \\
\hline & $<10$ hours & 153 & 418 & & \\
\hline $\begin{array}{l}\text { Sleep duration in exam } \\
\text { period on weekdays }\end{array}$ & $\geqq 10$ hours & 44 & 45 & 19.406 & 0.000 \\
\hline & $<10$ hours & 167 & 459 & & \\
\hline $\begin{array}{l}\text { Sleep duration in non-exam } \\
\text { period on weekends }\end{array}$ & $\geqq 10$ hours & 128 & 300 & 0.087 & 0.769 \\
\hline & $<10$ hours & 94 & 210 & & \\
\hline $\begin{array}{l}\text { Sleep duration in exam } \\
\text { period on weekends }\end{array}$ & $\geqq 10$ hours & 115 & 276 & 0.475 & 0.491 \\
\hline & $<10$ hours & 108 & 232 & & \\
\hline $\begin{array}{l}\text { Sleep duration in non-exam } \\
\text { period on weekdays }\end{array}$ & $\geqq 9$ hours & 202 & 380 & 3.343 & 0.067 \\
\hline & $<9$ hours & 52 & 137 & & \\
\hline $\begin{array}{l}\text { Sleep duration in exam } \\
\text { period on weekdays }\end{array}$ & $\geqq 9$ hours & 139 & 240 & 19.504 & 0.000 \\
\hline & $<9$ hours & 73 & 265 & & \\
\hline $\begin{array}{l}\text { Sleep duration in non-exam } \\
\text { period on weekends }\end{array}$ & $\geqq 9$ hours & 179 & 461 & 14.353 & 0.000 \\
\hline & $<9$ hours & 44 & 49 & & \\
\hline $\begin{array}{l}\text { Sleep duration in exam } \\
\text { period on weekends }\end{array}$ & $\geqq 9$ hours & 176 & 440 & 6.914 & 0.009 \\
\hline & $<9$ hours & 47 & 68 & & \\
\hline
\end{tabular}

Note: $\mathrm{df}=1$ for all variables

As revealed in Table 3, during non-exam periods on weekdays, only $142(19.9 \%)$ children attained the recommended 10 hours or more of sleep, versus $571(80.1 \%)$ who did not $\left(x^{2}=9.748 ; d f=1, P=0.002\right)$. In exam periods on weekdays the situation was worse, as $626(87.6 \%)$ children did not get the recommended 10 hours, while only $89 \operatorname{did}\left(\mathrm{x}^{2}\right.$ $=19.406 ; \mathrm{df}=1, \mathrm{P}=0.000$ ). No significant differences, however, were seen on weekends in the percentages of students who did or did not get 10 hours of sleep in exam or non-exam periods.

When a 10-hour duration of sleep was the cutoff, both private and public school students were usually in the category of $<10$ hours in both exam and non-exam periods on weekdays. With 9 hours as the cutoff, for both non-exam and exam periods on weekdays and weekends, public school 
students were always more congregated in the higher group ( $\geq 9$ hours), while private school students were in the higher group in three of the four categories (all but exam period on weekdays).

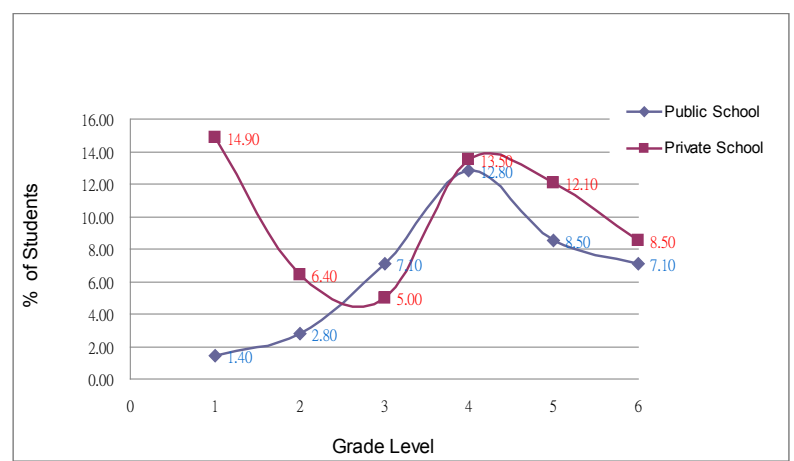

Figure 1. Percentage of students who slept 10 hours or more during the weekdays in non-exam periods at different grade levels $(\mathrm{N}=710)$

As shown in Figure 1, during weekdays in non-exam periods, at every level except grade three, private school students had a higher percentage (albeit not always significantly so) of getting $\geq 10$ hours of sleep (in grade one, only $14.9 \%$ of private school students and just $1.4 \%$ of public school students got this much sleep. The significant differences between public and private schools in getting $\geq 10$ hours of sleep in non-exam periods on weekdays: $\mathrm{x}^{2}(\mathrm{df}=5, \mathrm{~N}=142)=$ $13.84, \mathrm{P}=0.017$. The percentage was calculated based on 56 and 85 students in public and private schools that had $\geq 10$ hours of sleep ranging from primary grades one to six.

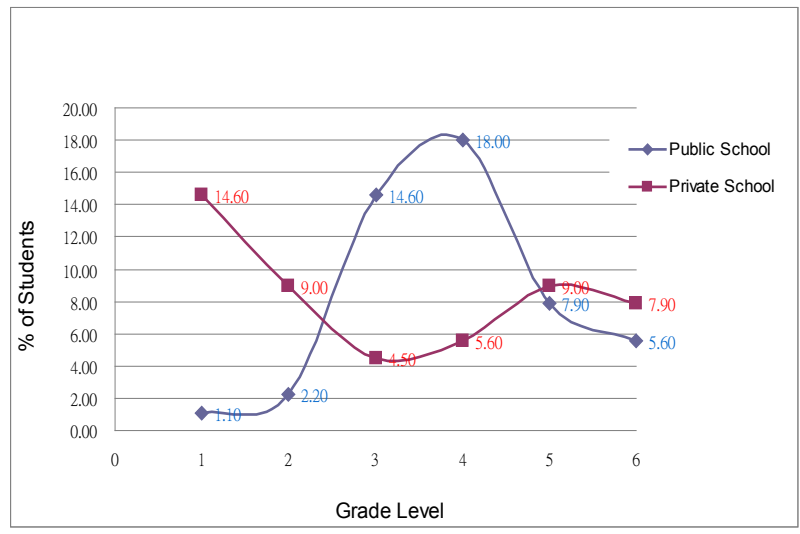

Figure 2. Percentage of students who slept 10 hours or more during the weekdays in exam periods at different grade levels $(\mathrm{N}=710)$

As shown in Figure 2, in grade one, the proportion of students in public schools who got $\geq 10$ hours of sleep during exam periods on weekdays was just $1.10 \%$, versus $14.60 \%$ of private school students. And yet, in grades three and four the results were very much reversed $(14.60 \%$ for public school and just $4.50 \%$ for private school in grade three; $18.00 \%$ and $5.60 \%$ in grade four, respectively). The significant differences for sleep duration(cutoff: 10 hours) between public and private students in exam periods on weekdays: $\mathrm{x}^{2}(\mathrm{df}=5$, $\mathrm{N}=89)=24.804, \mathrm{P}=0.000$.

Another significant difference shown in Table 3 had to do with not getting enough sleep in exam periods on weekdays when the cutoff was 10 hours: $x^{2}(d f=5, N=626)=24.804, P$ $=0.000$.

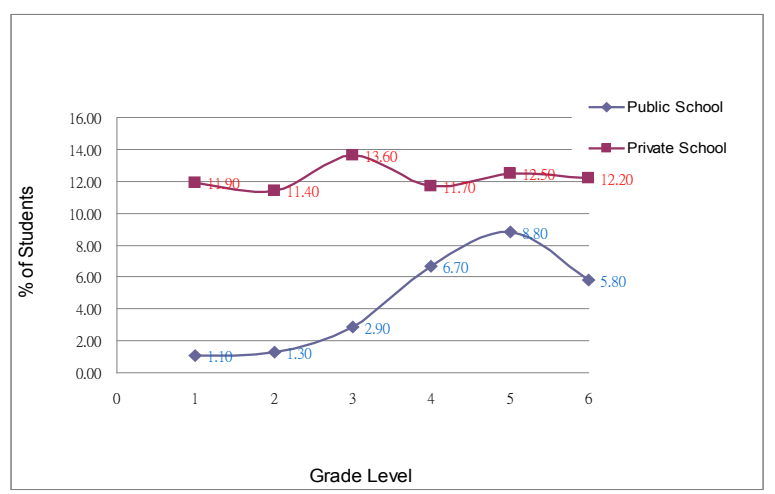

Figure 3. Percentage of students who slept less than 10 hours during the weekdays in exam periods by grade levels $(\mathrm{N}=710)$

As shown in Figure 3, in the earlier grades the percentage of public students who failed to get 10 hours of sleep rose until grade five, and then declined. In contrast, in the private schools, greater age did not seem to make much difference.

\subsection{Discussion}

This study indicates that, on weekdays, Macao primary students generally fail to get the recommended 10 hours of daily sleep. We also found that Macao public school students in grades one and two have very low rates of reaching this recommendation. By type of school, it appears that public students do better than private students overall in getting enough sleep. It seems fair to assume that private schools require a more stressful workload for their primary students than is imposed on public school students. In terms of grade level, one can imagine that very young students would have a particularly difficult time in coping with the demands of school, but why private school students would fare so much better than their public school counterparts in these grades is unclear.

The two private schools selected for this study in Macao are both considered "popular schools" and thus have better educational systems than the public schools. The private schools are popular among parents for being quite strict in enrollment, offering considerable quality in teaching skills, and making high demands on the children, with a heavy load of schoolwork, tests, and exams. The parents of the children in these schools were even willing to queue up for hours to get them enrolled. From the demographic data we obtained for this study, the background of the private school children was mostly middle or upper socioeconomic status. They had higher than average grades, even with extremely heavy demand from the schools, and they had more times per week of extracurricular activities than did the public students. Facing demands and even hardship from the schools and their parents, they still enjoyed school life very much and lived harmoniously with their schoolmates. In the categories we analyzed, private school students usually had higher scores (than public students) in the so-called 'better" variables, such as taking a shower and brushing their teeth, 
and lower scores in feeling sleepy even with an inadequate amount of sleep, being unable to concentrate in class, having the same wake-up time on school weekdays and weekends, neighborhood noise, having their sleep affected by their parents arguing, and being affected by an uncomfortable bedroom.

We found that children in private schools were more likely than their public counterparts to delay bedtime because of a test or exam and to have their parents wake them up. They also scored higher on items that involved the companionship of their parents, including falling to sleep easily with such companionship. We might surmise that many of these students had a hard time falling asleep and that sometimes to shorten this time, their parents accompanied them to bed. As many of the private school children delayed bedtime because of tests or exams, this practice could be seen as efficient: the children already did not have more time to waste, and they had to wake up early for school. This habit of "cosleeping" has been supported by research studies that included Italian, U.S., and Korean children[8,26-29]

Our finding that students in private schools were more often required to attend private lessons after school is consistent with the private students carrying a heavy school workload. We might conclude that they needed private lessons after school to assist them with their learning, but the desires of their parents for their children's academic success must be considered. Our finding about private lessons is consistent with other studies set in Asian countries, such as mainland China, Korea, and Japan[2-3,30] In our study we found that private school students were more likely than their public counterparts to arrive home late after finishing their private lessons and to not be allowed to watch TV or play computer games on school days. These findings are consistent with the notion that the private schools are more demanding than public schools in workloads and requirements for educational knowledge. The findings, while statistically significant, were $42.1 \%$ of private and $37.8 \%$ of public could not watch TV or play computer-games on school days. As for the three environmental factors described above, in all cases the differences between private and public students were highly significant, and the percentages for private school students on these undesirable factors ranged from just 10.0 to $14.9 \%$, versus $20.7 \%$ to $29.8 \%$ for public students.

According to research studies, low socioeconomic class might result in sleep of poor quality and lower quantity, with the consequences being hyperactive behavior and low grades in school[31] Per our study, the sleep behavior of students in the public schools was more frequently affected by environmental factors than was the case in the private schools, and the affected students might have had a hard time falling asleep or may not have enjoyed sleep of good quality. Notably, the students in public schools were more likely to feel sleepy even with adequate sleep $38.2 \%$ versus $27.3 \%)$ and to be unable to concentrate in class $(24.1 \%$ versus $18.3 \%$ ). These factors would be consistent with their lower average grades, although one would certainly not treat them as complete explanations. Other factors that could have affected the public students to a greater degree than private students, although we have no direct evidence from our study, might have been small living quarters with overcrowding and numerous family members. The stress of parents having frequent arguments would no doubt affect the children's sleep, and siblings or family members sharing the bedroom but on a different bedtime schedule would definitely affect the children's ability to initiate sleep[32] Furthermore, with inadequate financial support for paying their electrical bills, the bedrooms of public school children might not be set up with adequate air conditioning[7,33], although we did not study this specifically. The result was supported that socioeconomic status has great risks to the sleep behaviour among primary school-aged children[34] Inadequate sleep may contribute poor school performance[35], however, other physical behaviour and neuropsycholoigc problems may affect the quality of sleep[36]

We should note that with all of the problems faced by public school children, they actually fared better than the children in private schools in terms of sleep duration on weekdays. Even so, both groups did very poorly on an objective basis. According to the[8], children should get at least 10 to 11 hours of sleep per night; in the present study, however, only 142 of 713 primary students in public and private schools combined reached the 10-hour standard in non-exam periods on weekdays, or one out of five. During exam periods on weekdays, not surprisingly, the situation was worse, as only one out of eight reached the standard. Thus, four out of five children had inadequate sleep on one measure and seven of eight on the other. These results were far worse than those reported by the National Sleep Foundation, which found that only $24 \%$, essentially one-fourth, of children slept less than the recommended hours at night. They were not, however, greatly discordant with those from previous studies conducted in Asian countries. Notably, we found that $55.1 \%$ of private students and $34.8 \%$ of public students agreed that their school workload greatly affected their bedtime. Finally, we found that the percentage of students who achieved 10 or more hours of sleep on weekends $(58.6 \%)$ was far greater than it was on weekdays, as described above.

\subsection{Limitation}

Although the two private schools considered here were both "popular" institutions, there are other private schools in Macao that might be considered even more representative of "popular." Another concern is that we could not include many students from the public schools who were in grade one or two. The reason is that at that time there were numerous students who were running a temperature and thus forced to stay at home. In addition, there was one class only in grade one and grade two. That was related to the low enrollment rate in public schools in recent years. Another issue of concern is that the parents of the students in public schools might not have had an adequate educational back- 
ground to complete the survey. Interestingly, $22.0 \%$ of the surveys in the public schools were filled out by public school students, while $19.5 \%$ of the surveys in the private schools were completed by private school students, even though there were far more private school than public school surveys completed: $x^{2}(d f=3, N=749)=136.175$, $\mathrm{P}$ $=0.000$. Perhaps in lower grades one to three in the public schools especially, the students were not able to fully understand the questions and could not complete the questionnaire. The questions/items were checked and tested previously so that students in primary grade four and above could totally understand them and complete the survey except the item on monthly income. No parents' education was asked in the survey, therefore, further study should be investigated with this issue whether the higher parents' education might have correlation with sleep behavior of children.

\section{Conclusions}

The results of this survey indicate that the management of the schools in Macao and actions of the parents definitely affected the sleep behavior of the students. Perhaps surprisingly, sleep duration was even worse in private schools than in public schools, even though the socioeconomic background was better in private schools. One can assume that parents with students in either the private or public schools were lacking in knowledge about the importance of sleep. Students from private schools had even shorter duration of sleep during exam periods on weekdays and weekends. Our study indicates that students in private schools were under more academic pressure than their counterparts in public schools. The fact that the private school students were mostly from the middle socioeconomic class might have contributed to having their parents push them in school. Furthermore, public school parents might not be able to manage their children well or may lack the time to do so, which might be reflected in their lower grades in school. Health professionals as well as teachers should be alert to the fact that abnormal health or impaired physical or psychological development might be correlated with inadequate sleep as defined by its duration or quality. Finally, parents should be educated about what proper sleep behavior is and how it will help their children to obtain good school assessments in the long run.

\section{ACKNOWLEDGEMENTS}

The author would like to thank the Macao Polytechnic Institute for funding this study (RP/ESS/2007). The author would also like to acknowledge all the participants conducting this survey.

\section{REFERENCES}

[1] Humphreys JC, and Lee KA (2006) Sleep of children of abused women in transitional housing. Pediatric Nursing 32(4): $311-316$

[2] Qian HZ and Yu W (2004) Epidemological study of sleep behaviors in Guangzhou of children aged 2-12 years. Journal of Applied Clinical Pediatrics (in Chinese) 19: 1078-1080

[3] Liu X, Liu L, Owens JA and Kaplan DL (2005) Sleep patterns and sleep problems among schoolchildren in the United States and China. Pediatrics 115(1 Suppl): 241-249

[4] Rugg-Gunn AJ, Hackett AF, Appleton DR, and Eastoe JE (1984) Bedtimes of 11 to 14-year-old children in north-east England. Journal of Biosocial Science 16: 291-297

[5] Sun YH, Hua P, and Ni JF (1995) Research in pathophysiology of sleep pattern among partial students in secondary school of Hefei city. From: A medical university newspaper (in Chinese) 30(6): 87

[6] Zhou K, Yu XM and Ye G.J (1997) School assignment workload causing students behaviour problems in a secondary school. Chinese School Health (in Chinese) 18: 208-209

[7] Leger D and Pandi-Perumal SR (2007) Sleep Disorders: Their Impact on Public Health. Informa Healthcare, London 1-17

[8] National Sleep Foundation: Sleep in America poll (2004). Retrieved on November 19, 2007, from http://www.sleep foundation.org

[9] Brand S, Frei N, Hatzinger $M$ and Holsboer-Trachsler E (2005) Adolescents' self-reported sleep quantity and sleep-related personality traits - a pilot study. Somnologie 9: 166-171

[10] Manni R, Ratti MT, Marchioni E, Castelnovo G, Murelli R, Sartori, Galimberti A and Tartara A (1997) Poor sleep in adolescents: a study of 869 17-year-old Italian secondary school students. Journal of Sleep Research 6(1): 44-49

[11] Ghanizadeh A, Kianpoor M, Rezaei M, Rezaei H, Moini R, Aghakhani K, Ahmadi J, and Moeini SR (2008) Sleep patterns and habits in high school students in Iran. Annals of General Psychiatry 7: 5

[12] Meijer AM, Habekothe HT and van den Wittenboer G.L (2000) Time in bed, quality of sleep and school functioning of children. Journal of Sleep Research 9(2): 145-153

[13] Paavonen EJ, Nieminen-von Wendt T, Vanhala R, Aronen ET and von Wendt $L$ Effectiveness of melatonin in the treatment of sleep disturbances in children with Asperger disorder. Journal of Child and Adolescent Psychopharmacology 13(1): $83-95$

[14] Gao F (2000) Survey of students' sleep patterns in my school. Journal Chinese School Doctor (in Chinese) 14: 399

[15] Quine L (2001) Sleep problems in primary school children: comparison between mainstream and special school children. Child: Care, Health and Development 27(3): 201-221

[16] Yang CK, Kim JK, Patel SR and Lee JH (2005) Age-related changes in sleep/wake patterns among Korean teenagers. Pediatrics 115(1 Suppl.): 250-256 
[17] Dahl R (1998) Common sleep problems in children. In: J. S. Poceta and M. M. Mitler (eds) Sleep Disorders: Diagnosis and Treatment. Humana Press, Towata, NJ, 161-186

[18] Didden R, Korzilius H, van Aperlo B, van Overloop C and de Vries M (2002) Sleep problems and daytime problem behaviours in children with intellectual disability. Journal of Intellectual Disability Research 46(Part 7): 537-547

[19] Kirov R, Kinkelbur J, Heipke S, Kostanecka-Endress T, Westhoff M, Cohrs S, Ruther E, Hajak G, Banaschewski T and Rothenberger A (2004) Is there a specific polysomnographic sleep pattern in children with attention deficit/hyperactivity disorder? Journal of Sleep Research 13(1): 87-93

[20] Meijer AM, Habekothe HT and van den Wittenboer G.L (2001) Mental health, parental rules and sleep in pre-adolescents. Journal of Sleep Research 10: 297-302

[21] Shang C, Gau SS and Soong W (2006) Association between childhood sleep problems and perinatal factors, parental mental distress and behavioral problems. Journal of Sleep Research 15: 63-73

[22] Bates JE Viken RJ Alexander DB Beyers J and Stockton L (2002) Sleep and adjustment in preschool children: sleep diary reports by mothers relate to behavior reports by teachers. Child Development 73: 62-74

[23] Montgomery E and Foldsfang A (2001) Traumatic experience and sleep disturbance in refugee children from the Middle East. European Journal of Public Health, 11: 18-22

[24] Brown FC, Buboltz Jr WC and Soper B Relationship of sleep hygiene awareness, sleep hygiene practices, and sleep quality in university, 2002. Retrieved on February 25, 2008, from http://www.encyclopedia.com/pritable.asps? $\mathrm{id}=1 \mathrm{G} 1: 92724721$

[25] Ledoux S, Choquet M and Manfredi R (1994) Self-reported use of drugs for sleep or distress among French adolescents. Journal of Adolescent Healt 15(6): 495-502

[26] Cortesi F Giannotti F Sebastiani T and Vagnoni C (2004)
Cosleeping and sleep behavior in Italian school-aged children. Journal of Developmental \& Behavioral Pediatrics 25: 28-33

[27] Giannotti F, Cortesi F, Sebastiani T and Vagnoni C (2005) Sleeping habits in Italian children and adolescents. Sleep Biological Rhythms 3: 15-21

[28] Lozoff B, Askew GL and Wolf AW (1996) Cosleeping and early childhood sleep problems: effects of ethnicity and socioeconomic status. Journal of Developmental \& Behavioral Pediatrics 17(1): 9-15

[29] Yang CK and Halm HM (2002) Cosleeping in young Korean children. Journal of Developmental \& Behavioral Pediatrics 23: $151-157$

[30] Gaina A, Sekine M, and Hamanishi S, Chen X, Wang H, Yamagami T and Kagamimori S (2007) Daytime sleepiness and associated factors in Japanese school children. Journal Pediatric 151(5): 518-522

[31] Wolfson AR and Carskadon MA (1998) Sleep schedules and daytime functioning in adolescents. Child Development 69(4): 875-887

[32] Williams DR, Yu Y, Jackson JS and Anderson NB (1997) Racial differences in physical and mental health: socio-economic status, stress and discrimination. Journal of Health Psychology 2(3): 335-351

[33] Reite M, Ruddy J and Nagel K (2002) Concise Guide to Evaluation and Management of Sleep Disorders. American Psychiatric Publishing, Inc., Arlington, VA, (third edition)

[34] Li AM, Au CT, So HK, Lau JL, Ng PC and Wing YK (2010) Prevalence and risk factors of habitual snoring in primary school children. Chest 138: 519-527

[35] Anderson B, Storfer-Isser A, Taylor G, Rosen CL and Redline S (2009) Association of executive function with sleepiness and sleep duration in adolescents. Pediatrics 123: e701-707

[36] Halbower AC (2010) The clustering of disorders related to childhood sleep-disordered breathing: are they related to a single mechanism? Chest 138: 469-471 